\title{
The Research on Strategic Human Resource Management and the HR Scorecard
}

\author{
Peng Cui ${ }^{1, a}$ \\ ${ }^{1}$ School of Business management, Tonghua Normal University, China \\ adbcy9999@163.com
}

\begin{abstract}
Keywords: competitive advantage, HR scorecard strategic control, strategic management, strategic plan.
\end{abstract}

\begin{abstract}
This paper explains how to design and develop an HR system that supports the company's strategic goals. It explains the strategic management process, how to develop a strategic plan, and the HR manager's role in the process in strategy execution and formulation. It discusses how to create a strategy oriented HR system and reviews the HR scorecard approach to creating a strategy oriented HR system.
\end{abstract}

\section{HR's Strategic Challenges}

A strategic plan is the company's plan for how it will match its internal strengths and weaknesses with external opportunities and threats in order to maintain a competitive advantage [1-2]. The HR strategy needs to support the company's strategic plan. In formulating their HR strategies [3], HR managers must address three basic challenges: 1) support corporate productivity and performance improvement efforts; 2) employees play an expanded role in employers' performance improvement efforts; 3) HR must be more involved in designing - not just executing - the company's strategic plan.

A. The Strategic Management Process:

Strategic management [4-7] is the process of identifying and executing the organization's mission, by matching the organization's capabilities with the demands of its environment. It consists of several related tasks:

1. Define the Business and Its Mission - Managers choose strategies to get the company from where it is to where it wants to be tomorrow. The company's vision is a general statement of its intended direction that evokes emotional feelings in organization members. The mission is more specific and shorter term, communicating "who we are, what we do, and where we're headed"

2. Perform External and Internal Audits - SWOT analysis is a commonly used tool that identifies the company's strengths and weaknesses, opportunities and threats.

3. Translate the Mission into Strategic Goals - Operationalize the mission by getting specific around goals.

4. Formulate a Strategy to Achieve the Strategic Goals - A strategy is a course of action, showing how the enterprise will move from where it is now to where it wants to be as stated in its vision, mission and strategic goals, given its opportunities, threats, strengths and weaknesses.

5. Implement the Strategy - Translating the strategies into actions and results.

6. Evaluate Performance - Assessing progress toward strategic goals and taking corrective action as needed. Strategic control keeps the company's strategy up to date, and identifies where adjustments need to be made

B. Types of Strategic Planning - Managers have three levels of strategic planning.

1. Corporate-level strategy - Identifies the portfolio of businesses that comprise the company and the ways in which these businesses related to each other. Diversification, vertical integration, consolidation and geographic expansion are all examples of corporate level strategies.

2. Business-level/competitive strategy - Identifies how to build and strengthen the business's long term competitive position in the marketplace. Companies try to achieve competitive advantages for the business they are in, which allow them to differentiate its product or services from those of its 
competitors to increase market share. Examples of competitive strategies include cost leadership and differentiation.

3. Functional strategies - identify the basic course of action that each department will pursue in order to help the business attain its competitive goals.

When you're On Your Own: Using Computerized Business Planning Software. There are several business planning software packages available to help the small business owner write top-notch strategic and business plans.

C. Achieving Strategic Fit

Strategic planning [8-10] experts have different views on fitting capabilities to the opportunities and threats vs. stretching beyond capabilities to take advantage of an opportunity.

1. The "fit" point of view, as purported by Michael Porter, states that all of the firm's activities must be tailored to or fit its strategy by ensuring that the firm's functional strategies support its corporate and competitive strategies.

2. Other strategy experts Hamel argue for "stretch", suggesting that leveraging resources can be more important than just fitting the strategic plan to current resources.

D.HR and Competitive Advantage

In order to have an effective competitive strategy, the company must have one or more competitive advantages. Technology itself is rarely enough to set a firm apart as most companies today have easy access to the same technologies, so that the real differentiation is people and the management system.

E. Strategic Human Resource Management

HR strategies refers to the specific courses of action the company pursues to achieve its aims. It means formulating and executing HR systems that produce the employee competencies and behaviors the company needs to achieve its strategic aims.

\section{HR's Strategic Roles}

Human Resources is increasingly assuming more strategic planning responsibilities and involvement in the process. Among their contribution to strategic planning are identification of human issues that are vital to the business strategic, helping to establish and execute strategy, and forecast potential obstacles to success. HR Managers can provide alternative insights and are centrally involved in creating responsive and market driven organizations. In order to play this role, HR managers need an in-depth understanding of the value creating proposition of the firm.

Strategy execution is traditionally the heart of the HR manager's strategic planning job. The company's HR strategies should flow directly from its company-wide and competitive strategies. HR increasingly plays an expanded strategic planning role, to include working with top management to formulate the company's strategic plans. Formulating a company's strategic plan requires identifying, analyzing, and balancing the company's external opportunities and threats on the one hand and its internal strengths and weaknesses on the other.

HR Management is in a unique position to supply competitive intelligence that may be useful in the strategic planning process, such as competitors' incentive plans, pending legislation, and the company's internal human strengths and weaknesses. By working closely with top management, HR is able to build a persuasive case through a strategy oriented HR system to shows how the firm's HR activities contribute to creating value for the company.

\section{Creating a Strategy Oriented HR System}

Behaviors and competencies that the company's strategy requires that emerge from the actions and policies of the firm's strategy-supporting HR system.A. The High Performance Work System Managers and HR experts advocate that the HR system itself be a high-performance work system, maximizing the overall quality of human capital throughout the organization. 
Evidence suggests that high performance HR practices, combined with new technology, produce better productivity, quality, sales, and financial performance. Practices include high-involvement organizational practices, high-commitment work practices, and flexible work assignments, as well as practices that foster skilled workforces and expanded opportunities to use those skills.

Translating Strategy into HR Policy and Practice - The basic model of how to align HR strategy and actions with business strategy is outlined in Figure. HR management formulates HR strategies, policies, and practices aimed at achieving the desired workforce skills, attributes, and behaviors. Metrics are identified which can be used to measure the extent to which new HR initiatives are supporting management's strategic goals.HR Strategy in Action: An Example - This example illustrates how Einstein Medical's HR managers formulated and used HR strategies to execute strategic plans. The example explains how the vision to change the organization into a comprehensive healthcare network providing a full range of high-quality services in various local markets required numerous changes in the organization and human resources. Behavioral outcomes by the CEO from which HR developed five key HR strategies aimed at creating the required employee competencies, skills and behaviors. Specific programs and practices were then developed by HR which contributed directly to achieving the organization's strategic aims.

\section{The HR Scorecard Approach}

HR creates value by engaging in activities that produce the employee behaviors the company needs to achieve strategic goals. Managers use an HR Scorecard to measure the HR function's effectives and efficiency in producing these employee behaviors and thus in achieving the company's strategic goals. The HR Scorecard - shows the causal link between the HR activities, and the emergent employee behaviors, and the resulting firm-wide strategic outcomes and performance. Creating an HR Scorecard - Three types of information are needed to create an HR Scorecard. Using the HR Scorecard Approach - There are seven steps involved in using the HR Scorecard .This illustrates how the multi-stop process for developing an HR Scorecard works. As a corporate strategy, the management and owners want to continue to expand geographically, believing that doing so will allow them to capitalize on their reputation for good service, by producing multi-city alternatives for guests.

1. The Strategy - The strategy chosen by management is to use superior guest services to differentiate their properties, and increase the length of stays and return rate of guests, thereby boosting revenues and profitability.

2. The Value Chain Inbound logistics activities getting guests from the airport and checked in, operations activities; outbound logistics activities, marketing and sales activities, service activities and support activities.

3. The Strategically Required Organizational Outcomes - the outcomes that the Hotel Paris is seeking includes fewer customer complaints, more written compliments, more frequent guest returns, longer stays, and higher guest expenditures per visit.

4. The Strategically Relevant Workforce Competencies and Behaviors - Based on the value chain analysis, competencies and behaviors identified are "high quality front-desk customer service", "taking calls for reservations in a friendly manner", "greeting guests at the front door", and "processing guests' room service meals efficiently".

5. The Strategically Relevant HR System Policies and Activities - Here HR deliverables are identified to produce the crucial workforce competencies and behavior. For example, in order to produce "high quality front-desk customer service," an HR deliverable of instituting practices to improve disciplinary fairness and justice in the company with the aim of improving employee morale is identified.

6. The HR Scorecard - Metrics are selected to show the links among the HR activities, workforce behaviors and organizational outcomes. 


\section{Summary}

The Human Resource function today continues to play an increasingly visible role in the strategic planning and management process, requiring a new level of skill and competency among HR professionals. The author suggests that the most potent action HR managers can take to ensure their strategic contribution is to develop a measurement system that convincingly showcases HR's impact on business performance. To design such a measurement system, HR managers must adopt a dramatically different perspective that focuses on how human resources can play a central role in implementing the firm's strategy.

\section{Acknowledgement}

This research was supported by Research Foundation of Education Bureau of Jilin Province (Grant No.JJKH20170444SK).

\section{References}

[1] Nurul Nadia Abd Aziz; Sarminah Samad, Innovation and Competitive Advantage: Moderating Effects of Firm Age in Foods Manufacturing SMEs in Malaysia, Procedia Economics and Finance, 2016.

[2] Ayman Ahmed Ezzat Othman; Marise Hossam Hosny Sorial, Achieving competitive advantage through the integration of disabled architects in architectural design firms in Egypt, Organization, Technology and Management in Construction: an International Journal, pp. 1547-1558, 2017.

[3] Knorst; André Marcelo; Vanti, Adolfo Alberto; Andrade; Rafael Alejandro Espín; Johann; Silvio Luiz, ALIGNING INFORMATION SECURITY WITH THE IMAGE OF THE ORGANIZATION AND PRIORITIZATION BASED ON FUZZY LOGIC FOR THE INDUSTRIAL AUTOMATION SECTOR, ProQuest, pp. 555-580, 2011.

[4] František Ochrana; Michal Plaček; Milan Jan Půček, Shortfall of Strategic Governance and Strategic Management in the Czech Republic, Central European Journal of Public Policy, vol. 24, pp. 30-47, 2016.

[5] Sang Ok Choi, Emergency Management: Implications from a Strategic Management Perspective, Journal of Homeland Security and Emergency Management, pp. 1547, 2011.

[6] Jarosław Domański, M. Darwis, and K. Ertogral, The Analysis and Synthesis of Strategic Management Research in the Third Sector from Early 2000 Through to Mid-2009, Foundations of Management, pp. 27-40, 2011.

[7] Ivan Marković; Tatjana Stevanović, Strategic Management Accounting Role In The Performance Measurement And Control Of Multinational Companies, Economic Themes, vol. 27, pp. 436-460, 2014.

[8] Hanan H. Balkhy, The strategic plan for combating antimicrobial resistance in Gulf Cooperation Council States, Journal of Infection and Public Health, 2016.

[9] Susan Maxwell; Lynn G. Wellman; Merging Two Robust Women's Services in Alignment With a Comprehensive Nursing Strategic Business Plan, Journal of Obstetric, Gynecologic \& Neonatal Nursing, 2014.

[10] Guilin Chen; Shenghui Zhao; Effects of Informationization on Strategic Plan of Regional Universities, Springer, pp. 1073-1083, 2014. 